\title{
Behavioural Analysis of Criminal Law: A Survey
}

\author{
ALON HAREL*
}

\section{Introduction}

Behavioural analysis of criminal law exploits social science methodologies (behavioural economics, psychology and even sociology) to explore the effects of criminal law norms on criminals, judges, juries and other decision-makers, to determine the optimal type and size of criminal sanctions, to identify the optimal design of the enforcement system and the rules of evidence. Behavioural analysis of criminal law often addresses, criticises, or complements the findings of the traditional economic tools by using social sciences findings concerning the content of individuals' beliefs, and the content of their preferences. As criminals, policepersons, victims of crime, judges, and other relevant agents form beliefs concerning probability of detection and conviction, and those affect the propensity to commit crimes, enforcement policy, evidence law and procedural law are as relevant to the understanding of the effects of criminal law as the substantive doctrines of criminal law itself. Hence both the economic and the behavioural approaches to the analysis of criminal law challenge the traditional doctrinal distinctions between criminal law, criminal procedure and evidence and, last, the enforcement policy.

The behavioural approach to criminal law is founded on the research of behavioural economists, psychologists and sociologists. ${ }^{1}$ Unlike traditional neo-classical economics, the behavioural perspective is eclectic rather than unitary; it is composed of various psychological findings including cognitive biases and their effects, prospect theory, the effects

Phillip P. and Estelle G. Mizock Chair of Administrative and Criminal Law at the Hebrew University of Jerusalem.

For previous surveys of the behavioural approach to criminal law, see McAdams and Ulen, Behavioral Criminal Law and Economics, in 3 Criminal Law and Economics: Encyclopedia of Law and Economics 403, ed. Garoupa (Edward Elgar 2009) pp. 413-426, Garoupa, Behavioral Economic Analysis of Crime: A Critical Review, in EUR. J.L. \& ECON. 15: 5, 8, 12-13 (2003), Jolls, On Law Enforcement with Boundedly Rational Actors, in The Law and Economics of Irrational Behavior 268, eds. Parisi and Smith (Stanford University Press 2005) pp. 272-281. This survey differs however from these surveys as it aims also to explore the philosophical foundations of the field. For a general description of economic and behavioural approach to criminal law, see Harel, Economic Analysis of Criminal Law: A Survey, in Research Handbook on the Economics of Criminal Law, eds. Harel and Hylton (Edward Elgar 2012). 
of social norms, findings concerning the ways preferences and beliefs are being shaped and even studies concerning happiness. Behavioural theorists call for the exploitation of various cognitive misperceptions, biases and heuristics to increase the deterrent effect of criminal law prohibitions and sanctions and/or increase their effectiveness in other ways.

This survey starts by examining in part 2 the theoretical foundations of behavioural analysis of criminal law. I contrast behavioural analysis with retributive justice values and, then, I contrast the behavioural approach to criminal law with traditional neo-classical economic analysis of criminal law and point out the distinctive features of the former. Part 3 illustrates the ways in which various behavioural phenomena can be used to understand the effects of criminal law norms and to design criminal law in a way that serves its social goals, in particular deterrence. Part 4 examines critically the potential contribution of behavioural studies to the optimal design of the legal system.

\section{Theoretical foundations}

To understand the contribution of behavioural analysis of criminal law to the study of law one needs to point out what is distinctive about behavioural analysis of criminal law, namely in what ways behavioural analysis modifies the ways criminal law should be understood and/or reformed. In the first section of this Part, I contrast economic/behavioural analysis of criminal law with the traditional doctrinal/analytic approach based on retributive justice. In the second section I contrast the behavioural approach with its older relative - the traditional economic approach to criminal law - and examine the commonalities and the differences between these two fields.

\subsection{Criminal law versus the economic/behavioural analysis of criminal law}

The traditional criminal law theorist believes that the criminal law primarily guides people and instructs them. Criminal law sanctions ought to be imposed on agents who committed wrongful acts because they 'deserve' to be punished, and the severity of the criminal sanction ought to be proportionate to the wrongfulness of the act and to the culpability of the actor. ${ }^{2}$

Some retributivists oppose using criminal law for the sake of realising any social goals including deterrence and/or just distribution, as such a use violates the basic Kantian principle under which one ought not use a person only as a means (not even as a means to deter or prevent crimes). ${ }^{3}$ It is unjust to inflict a sanction on the person simply because

2 Duff, Intention, Agency and Criminal Liability (B. Blackwell 1990) p. 103, Fletcher, Rethinking Criminal Law (Little, Brown and Company 1978) pp. 454-459, Nozick, Philosophical Explanations (Harvard University Press 1981) pp. 363-397.

3 Rauscher, Kant's social and Political Philosophy, in Stanford Encyclopedia of Philosophy, available at http:// plato.stanford.edu/entries/kant-social-political/ (last visited 12.5.2014). 
such a sanction brings about socially desirable outcomes; the only justification for such a sanction is that the person 'deserves' it.

This view contrasts sharply with the view of law and economics and behavioural theorists. Under their view, criminal law is a mechanism for preventing/deterring undesirable behaviour. ${ }^{4}$ Most typically criminal law norms (as well as other legal norms) are perceived as incentives for individuals to behave in a way that is socially optimal. A state of affairs that is socially optimal is often identified with efficiency, but it need not be identified only with efficiency. Distributive justice concerns could also be regarded as a legitimate goal of the economic/behavioural analysis. ${ }^{5}$

Unlike the retributivist tradition which often regards punishment as desirable in itself irrespective of its consequences, economic and behavioural approaches regard punishment as evil in itself (given its costs to society and to the criminal) but, it is at times a necessary evil to deter or prevent crime. ${ }^{6}$

By regarding efficiency (or any other social goals) as the primary (or even exclusive) consideration underlying criminal law, economic analysis of law as well as behavioural analysis conflict with the retributivist tradition and, such a conflict inevitably triggers incongruities between criminal law as it is commonly justified and understood and the economic/behavioural approach to criminal law. Let me briefly explore two examples of such incongruity.

The first incongruity touches upon fundamental assumptions concerning human rationality. In different ways the traditional criminal law approach and the law and economics approach are founded on assumptions concerning rationality. In contrast the behavioural approach relies heavily on the irrationality of agents or, at least on assumptions concerning 'bounded rationality', namely, on the existence of limitations on rationality. Most typically, the behavioural approach to criminal law often calls for exploiting cognitive errors and irrational human dispositions to deter or prevent crime. The policy recommendations of behavioural theorists in such cases are founded often on methods that can be described as manipulative and fraudulent. For instance it was argued that to deter parking violations one ought to use 'tricks' such as using 'large, bright orange tickets that

4 This view follows the utilitarian theory developed by Bentham, An Introduction to the Principles of Morals and Legislation 74, eds. Burns and Hart (1996). Becker, Crime and Punishment: An Economic Approach, in Journal of Political Economy 76:169-217 (1968), used contemporary neo-classical economics tools to develop Bentham's insights. For a more legally informed doctrinal analysis of criminal law along these lines, see Posner, An Economic Theory of Criminal Law, in Columbia L. Rev. 85:1193 (1985).

5 Harel, Efficiency and Fairness in Criminal Law: The Case for a Criminal Law Principle of Comparative Fault. California L. Rev. 82:1181, 1201-8 (1994), Harel and Parcharmovsky, On Hate and Equality. Yale L.J. 109:509 (1999).

6 This was already the view of Bentham 1996 who maintained: 'all punishment is mischief, all punishment in itself is evil'. Bentham also inferred from this observation the principle of 'frugality of punishment', namely that punishment ought to be as small as possible to achieve its social goals. I believe it is unfortunate that this principle has been forgotten by contemporary legislators and judges. 
read 'VIOLATION' in oversize letters on the drivers' side window where they are clearly visible to other drivers passing by.' The availability heuristic discussed below predicts that such a tactic would lead agents to overestimate the prospects of a parking ticket. ${ }^{7}$

In contrast, classical retributivism is often based on claims concerning the rationality of individuals and their capacity to make informed moral judgments and act on their basis. Arguments concerning 'free will' of individuals and their capacity to make autonomous choices are deeply entrenched in the retributivist tradition. To illustrate, Antony Duff's 'communicative theory' justifies punishment by pointing out that punishment conveys moral condemnation of the wrongful act. ${ }^{8}$ The criminal process is described in his theory as a dialogue between the state and the criminal in which the state provides arguments and the criminal responds to these arguments.

The second important incongruity between criminal law as understood by traditional criminal law theorists and the economic/behavioural approach to criminal law focuses on what counts as punishment. The retributivist believes that punishment ought to be inflicted because criminals 'deserve' their punishment, and hence that what counts is the ex-post sanction - the actual punishment inflicted on the criminal. The retributivist acknowledges of course that sometimes the criminal is not detected and, hence, no punishment is inflicted. But once detected the criminal ought to suffer in proportion to the gravity of the crime. In contrast, economic and behavioural theorists of law regard criminal law as an instrument designed to provide optimal incentives. The sanctions that are relevant for their enterprise are the ex-ante sanctions - the expected punishment taking into account the probability of detection. Harsher actual sanctions are necessary therefore to the extent that the probability of detection is low and vice versa.

It follows from this analysis that distinctions that are central to legal doctrine such as the distinction between substantive criminal law, procedural law, evidence law, and the design of enforcement institutions, are perceived by economists and behavioural scientists to be artificial. As the effectiveness of deterrence (as well as other social goals) hinges not only on the substantive doctrines of criminal law but also on the probability of detection and conviction, the law of evidence and the enforcement policy become central to the economic/behavioural analysis and are inseparable from the substantive doctrines of criminal law. One of the most interesting and somewhat counter-intuitive results of this approach is that under both the economic and the behavioural approach, the optimal size of the criminal sanction is inversely related to the probability of detection and conviction. This view differs sharply from the retributivist tradition, which believes that the actual (rather than expected) punishment ought to be proportionate to the wrongfulness of the act and the culpability of the actor.

Jolls, Sunstein and Thaler, A Behavioral Approach to Law and Economics. Stanford L. Rev. 50:1471 (1998).

Duff, Answering for Crime: Responsibility and Liability in the Criminal Law (Hart University Press 2007). 


\subsection{Economic versus behavioural approaches to criminal law}

The standard law and economics account of criminal behaviour begins with the observation that criminals (as well as other relevant agents such as judges, jurors, policepersons, and victims of crimes) are rational decision-makers. ${ }^{9}$ Rationality however is understood differently than the rationality as understood within the retributivist tradition. Rational individuals as understood within this tradition are self-interested; they decide whether to commit a crime on the basis of weighing the expected costs and benefits resulting from it. These costs and benefits are not merely monetary; they include non-monetary concerns including sadistic satisfaction, love of adventure risk, guilt feelings, stigma etc.

The traditional economic analysis of criminal law explains human behaviour in terms of the expected costs and benefits of crime. These costs and benefits include parameters such as the probability of detection, the size of the sanction, the attitudes of individuals towards risk, the expected costs of the sanctions, etc. The basic premise of this analysis is that individuals make rational judgments on the basis of these parameters and guide their behaviour accordingly.

Many of the behavioural theories examined in this article challenge this claim. For instance, it is pointed out that the expected sanctions do not guide people's behaviour in mechanical or predictable ways. Criminal law influences individuals by modifying their beliefs and preferences. If there are systematic biases that distort the judgments of individuals, such biases alter individual behaviour and result in irrational behaviour. False beliefs concerning the severity of the sanction, the probability of detection etc. would inevitably lead the criminal either to commit crimes it is irrational for him to commit or not to commit crimes it is rational for him to commit. Yet, behavioural theorists also believe that such biases are not erratic or arbitrary; they are predictable and therefore can be exploited by policymakers. At the same time, behavioural law and economics maintains that policymakers/legislators themselves are also subject to such cognitive biases and those distort their judgments. Note that in the present context, the terminology of 'biases' and 'distortion' is not meant to be normative but purely descriptive; it is meant to denote that the behaviour deviates from the assumptions of economic rationality.

The dichotomy between rationality and irrationality is not always precise or easy to draw. The controversy concerning rationality is complicated given that many of the distortions identified by behavioural scientists may be rational in the long run as they serve (at least in the long run) to promote the interests of the agents. They often reflect therefore a difference between rationality with respect to any individual decision and rationality in forming long-term rational strategies. ${ }^{10}$ pp. 38, 41 . 
The behavioural approach exploits empirical and experimental findings either to complement or, at times, to challenge the premise of rationality of human agents. The difference between complementing and challenging deserves attention. Behavioural scientists complement the findings by attributing to individuals certain preferences on the basis of psychological observations. Thus, for instance, behavioural scientists may establish that under certain circumstances individuals can be risk-averse or risk-loving depending on the way they frame a given choice or that they discount future benefits hyperbolically. These dispositions are not required by rationality but they are not precluded by it either. At times behavioural scientists go further and challenge the findings of economic theory by pointing out that individuals are 'irrational'; they form false or misguided beliefs which are not supported by the evidence at their disposal, (e.g., they are too optimistic); they assess probabilities on the basis of anecdotal evidence; they make decisions based on the ways circumstances are being presented to them (framing) and not on the basis of how things really are. In such cases individuals operate in ways that fail to maximise their own utility.

The boundaries between complementing and challenging the findings of economic theory are not always clear, as it is not always clear what choices are rational or irrational. While it is always intellectually appealing for behavioural theorists to describe their findings as refuting the rationality of the agents, the question of whether such findings complement economic theory (by identifying the actual beliefs and preferences of individuals) or establish that individuals are irrational (because their beliefs or preferences are 'irrational'), is less crucial than simply identifying the behavioural phenomena and their potential relevance to legislators, administrators, and judges.

\section{The behavioural approach to criminal law}

Being ultimately a critical methodology designed to complement and challenge the findings of economic analysis of law, one traditional way of presenting behavioural findings is by contrasting them with the findings of traditional economic theory. ${ }^{11}$ In the following discussion I shall follow this approach. At times however I will also contrast the behavioural findings with the retributivist tradition.

A word of caution: the behavioural analysis of law often applies general findings of behavioural science to the legal context. Psychologists investigate and make predictions as to how individuals act under uncertainty; what beliefs they form in different circumstances; what preferences they are disposed to adopt, etc. Legal theorists often apply these general predictions to the legal context. Such a methodology has risks as predictions concerning the behaviour of human beings are often sensitive to the context, and individuals

11 Harel, Economic Analysis of Criminal Law: A Survey, in Research Handbook on the Economics of Criminal law 10, 2012. 
facing a choice to commit a crime or to sentence criminals may behave differently than individuals facing choices in other contexts. To overcome this problem, behavioural law and economics theorists often examine empirically/experimentally the soundness of the general predictions in specific legal contexts. They do not apply automatically the general observations made by social scientists to the legal context. Instead they try to make independent investigations that involve legal uncertainty.

A much greater concern for the behavioural approach to law is the reliability of the behavioural method as such. Empirical/experimental research is currently a battlefield where different methodologies are being advocated and criticised, and theorists coming from different methodological schools expose deficiencies of other methodologies. This survey does not examine these debates and it will use indiscriminately research by theorists coming from different schools including in particular behavioural economics, cognitive psychology, and sociology. The reliability of one method or another is of course important but, as my aim is illustrative, it is not necessary to explore this issue here. The rest of this part 3 examines various behavioural phenomena that are relevant to criminal law doctrine or related fields.

\subsection{Behavioural findings and their relevance to criminal law}

As stated at the outset the behavioural analysis of law is an eclectic field. In this section I investigate various behavioural phenomena that are relevant to criminal law. The analysis is divided into two sub-sections. I first discuss behavioural phenomena that are individual and psychological, and then behavioural phenomena that are primarily sociological as they involve social interaction among individuals.

\subsubsection{Psychological findings and the law}

Behavioural observations on the optimal design of criminal sanctions and probability of detection

Criminal law differentiates sharply between the size of the sanction and the probability of detection and conviction. The size of the criminal sanction ought to reflect the seriousness and hideousness of the crime. The more hideous the crime, the harsher the sanction ought to be. Murder is ordinarily more serious wrong than burglary, and burglary is more serious than theft. The punishments for the different offences should reflect the hierarchy or gravity of the offence. Under this view, there is no relation between the probability of detection and conviction, and the size of the sanction. Empirical studies indicate that the traditional strict separation between these two questions reflects not only legal doctrine 
but also the moral intuitions of most people. Individuals believe that the size of the sanction ought not to depend on the probability of detection. ${ }^{12}$

Economic analysis of criminal law rejects this view. The primary purpose of criminal sanctions is to deter individuals from anti-social behaviour. Increasing the probability of detection and conviction, and increasing the size of the sanction, are both congenial to deterrence. Both the probability of detection and conviction and the size of the sanction determine the size of the expected sanction, and it is the expected sanction that matters from the perspective of deterrence. As the expected sanction should not exceed what is necessary for the purpose of deterrence, it follows that the harsher the sanction, the lesser the probability of detection and conviction ought to be, and vice versa.

The legal system ought to determine not only the size of the expected sanction but also the size of the expected sanction's components: the probability of detection and conviction on the one hand and the size of the sanction on the other. In his seminal article on the economics of criminal law, Gary Becker provides a simple, compelling, and highly counter-intuitive answer to this question. ${ }^{13}$ Under Becker's view, the answer to this question depends on the costs of increasing the size of the sanction on the one hand and increasing the probability of detection on the other. Becker maintains that if increasing the probability of detection is much more costly to society than increasing the size of the sanction, it follows that the legal system ought to inflict harsh sanctions even for the most trivial offences. ${ }^{14}$

The possibility that efficiency may under certain plausible conditions require increasing sanctions and reducing the probability of detection horrified even the most orthodox advocates of law and economics who tried hard to provide counter-arguments. For instance some theorists argued that harsh sanctions may have negative implications as they induce offenders to increase their investment in precautions, and therefore it may have negative effects on the probability of detection and conviction. ${ }^{15}$ Further it was argued that imposing harsh sanctions for all crimes undermines marginal deterrence; if I already committed a parking offence for which I am liable to be executed, I would not be deterred from committing more serious crimes, e.g., killing eyewitnesses. ${ }^{16}$

12 Sunstein, Schkade, and Kahneman, Do People Want Optimal Deterrence, in Journal of Legal Studies 29:237 (2000), Baron and Ritov, The Role of Probability of Detection in Judgments of Punishment, in Journal of Legal Analysis 1:553-90 (2009).

13 Becker, Crime and Punishment: An Economic Approach, in Journal of Political Economy 76:169-217 (1968) pp. $183-184$.

Ibid.

Mikos, Enforcing State Law in Congress Shadow, in Cornell L. Rev. 90:1411 (2005).

Posner, Economic Analysis of Law (Wolters Kluwer for Aspen Publishers 2007). I think that despite the fact that this is considered the standard and the most compelling efficiency-based reply to Becker's challenge this explanation fails. Even if the sanctions are harsh, marginal deterrence can be guaranteed by differen- 
The behavioural tradition addresses this concern differently. Behavioural scientists explore which components of the criminal sanctions have a greater deterrent effect: the probability of detection or the size of the sanction. More specifically, they argue that while both increasing the sanction and elevating the probability of detection affect criminal behaviour, they need not necessarily have identical effects.

To clarify this point, let us define the concepts of risk neutral, risk averse and risk loving individuals. An individual is risk neutral to sanctions if he is indifferent as to two sanctions with equal expected value. A fine of $\$ 10,000$ with a $1 \%$ probability of detection deters such an individual to the same degree as a fine of $\$ 100$ with a $100 \%$ probability of detection. An individual is risk averse if he is deterred more by a harsh sanction with a low probability of detection (e.g., $\$ 10,000$ with a $1 \%$ probability of detection) than by a light sanction with a high probability of detection (e.g., $\$ 100$ with a $100 \%$ probability of detection). A risk loving individual is deterred more by a light sanction with a high probability of detection (e.g., $\$ 100$ with a $100 \%$ probability of detection) than by a harsh sanction with a low probability of detection (e.g., $\$ 10,000$ with a $1 \%$ probability of detection). If individuals are risk averse, the policymaker can increase deterrence by imposing harsh sanctions with low probabilities of detection; if individuals are risk loving, deterrence may be increased by imposing light sanctions with high probabilities of detection.

Criminology research has been struggling with the question what has greater influence on criminal behaviour: the certainty or severity of the criminal sanctions. ${ }^{17}$ While empirical researchers debate this issue there are behavioural phenomena that support the claim that certainty should have greater effects than severity, namely that individuals are risk loving; they are deterred more by low sanctions with high probabilities of detection than by harsh sanctions with low probabilities of detection.

Take first the case of incarceration. Increasing the size of a sanction from a one-year to a two-year prison term does not double the deterrent effects of the sanction, because of a psychological phenomenon called discounting of the future. ${ }^{18}$ Compare Arthur, who expects to go to the dentist tomorrow and have a painful treatment, with Betty, who expects to go to the dentist next month. Arthur is anxious and wakes up at night anticipating the pain while Betty has no anxiety at this point. Individuals tend to discount the significance

tiating the probability of detection for light and grave offences, i.e. by investing greater effort in detecting grave offences. For another explanation along the lines of traditional law and economics, see Polinsky and Shavell, Optimal Use of Fines and Imprisonment, in Journal of Public Economics 24:89 (1984).

17 Grogger, Certainty vs. Severity of Punishment, in Economic Inquiry, v29 n2 (April 1991) pp. 297-309.

18 For an accessible explanation of discounting, see Shane, Loewenstein, and O'Donoghu, Time Discounting and Time Preference: A Critical Review, in Journal of Economic Literature XL:351-401 (2002). For an application to the case of incarceration, see Harel and Segal, Criminal Law and Behavioral Law and Economics: Observations on the Neglected Role of Uncertainty in Deterring Crime, in American Law and Economics Review 1:295 (1999). Some theorists raised the conjecture that long periods of imprisonment have very small deterrent effect because of 'hyperbolic discounting', see Garoupa 2003 pp. 12-13, Bronsteen, Buccafusco and Masur, Happiness and Punishment, in University of Chicago Law Review 76 no. 3 (2009). 
of distant future events. It follows that a second year of imprisonment (which inevitably starts only after the end of the first year) has a lesser deterrent effect than the first year (which starts immediately after conviction). A prison term of one year with a $2 \%$ probability of detection has a greater deterrent effect than two years with a $1 \%$ probability.

Another relevant explanation is based on the observation that legal sanctions are only part of the overall sanctions imposed on criminals. The criminal also suffers from stigma, which in turn often has both monetary and non-monetary effects on the criminal. ${ }^{19}$ Criminal conviction exposes the criminal to both legal and social sanctions. Assume that conviction exposes the criminal to a legal sanction of $\$ 100$ and to a social sanction worth $\$ 100$ to him. The sanction is effectively $\$ 200$. Assume also that the probability of detection is $1 \%$ and the expected overall sanction (consisting of the legal and non-legal sanction) is therefore $\$ 2$. If the state increases the legal sanction from $\$ 100$ to $\$ 200$, the overall sanction increases from $\$ 200$ to $\$ 300$ and the expected sanction increases as a result to $\$ 3$. Doubling the size of the (legal) fine in this case from $\$ 100$ to $\$ 200$ does not double the overall sanction. Yet doubling the probability from $1 \%$ to $2 \%$ would double the expected sanction from $\$ 2$ to $\$ 4$. Increasing the probability of detection has a greater effect on deterrence than increasing the sanction. ${ }^{20}$

\section{Behavioural effects of uncertainty: the punishment and the detection roulettes}

Criminal law tradition is committed to reducing as much as possible any uncertainty or unpredictability as to the scope of criminal offences and the size of the criminal sanction. Such certainty and predictability is required by principles of the rule of law and, consequently, such a principle is often entrenched in bills of rights and constitutions. ${ }^{21}$ On the other hand, there is no attempt on the part of the social planner to guarantee certainty with respect to the probability of detection or conviction.

To illustrate, consider the following example. Arnold and Betty commit an identical offence under similar circumstances. Arnold is sentenced to 10 years, while Betty is sentenced to 5 years. This gap seems unjust and may perhaps provide grounds for appeal. There is no reason why different sanctions are imposed on individuals who committed identical offences under identical circumstances. In contrast, assume that when Arnold commits the offence, police invest little in enforcement and, consequently, the probability of detection is low. The police then increase the investment in detection, and when Betty commits the offence, she is caught as a result of this special effort by the police. It is diffi-

On the dramatic monetary repercussions of criminal conviction, see Lott, An Attempt at Measuring the Total Monetary Penalty from Drug Convictions: The Importance of Individual Reputation, in Journal of Legal Studies 21:159-87 (1992).

20 Traditional law and economic theorists could easily accept such an analysis and, strictly speaking, this observation ought not to be classified as 'behavioural'. I include it here as some behavioural scientists often emphasise the significance of stigma.

$21 \quad$ Harel and Segal 1999 pp. $281-285$. 
cult to claim in such a case that Betty was discriminated against even if she could not have known when she committed the offence that the police would increase its investment in detection, and even if she can prove that she would not have been caught unless the police changed its enforcement policy.

Another indication of the difference between uncertainty with respect to the size of the sanction and uncertainty with respect to the probability of detection can be found in the information given to individuals. Criminal law provides information with respect to the size of criminal sanctions; it does not provide such information with respect to the probability of detection. Criminal law doctrine guarantees that the sanctions meted out would not be more severe than the one in force when the offence was committed, but it does not guarantee that the probability of detection remains fixed. It is a basic principle of criminal law (and it is part of the rule of law more generally) that increasing a sanction for a criminal offence does not apply retroactively. A potential criminal can 'rely' on the size of a sanction as is specified in the law at the time she commits the offence. On the other hand, typically no legal system allows a criminal to argue that the probability of detection increased after the offence was committed.

More generally, different legal ethos governs the size of legal sanctions and the probability of detection. The severity of the criminal sanction reflects the seriousness of the offence; hence, the legal system is committed to consistency in inflicting sanctions. Most importantly, it is committed to providing 'fair warning' to criminals with respect to the size of the criminal sanctions. The detailed American Sentencing Guidelines are perhaps the most evident manifestation of the commitment of the criminal law system to provide a fair and precise warning. On the other hand, the probability of detection is under the dominant tradition a function of pragmatic considerations, which change from time to time. The legal system rejects punishment roulettes and tries to guarantee certainty and predictability with respect to the size of the sanction. It does not, however, oppose detection roulettes and the probability of detection is subject to uncertainty.

The differential treatment of punishment on the one hand and probability of detection on the other hand appears natural to traditional criminal lawyers, but from an economic perspective it is puzzling. After all economic analysis of law regards both punishment and detection as components of the expected sanction. Why should there be such a major difference between the treatment of the size of the sanction and the probability of detection?

A natural way to justify the differential treatment is to explain it on behavioural grounds as an effective means to increase deterrence. This justification is based on the expected reaction of a criminal to punishment roulette on the one hand and probability of detection roulette on the other hand..$^{22}$ To illustrate, compare the two following legal systems. Under the first system, every convicted thief is sentenced to two years in prison. Under the second system, there is a sentencing roulette that inflicts a sanction of three 
years in prison on $50 \%$ of thieves and one year in prison on the other $50 \%$ of thieves. The expected sanction is two years in prison. Which system is more effective?

The answer to this question depends on the deterrent effects of each one of these systems. If thieves were risk averse, they would prefer the first system to the second system, and, consequently, sentencing roulette would have greater deterrent effect. If, on the other hand, thieves are risk loving they would prefer sentencing roulette, and therefore the deterrent effect of a certain sanction would be greater. Similar observations can be made with respect to the probability of detection roulette. If criminals prefer probability of detection roulette over a known probability (e.g., 50\% of the criminals are caught with a probability of $1 \%$ and $50 \%$ with a probability of $3 \%$ ), the deterrent effect of probability of detection roulette would be lower than the deterrent effect of a known probability (2\%) and vice versa.

We can now evaluate the desirability of sentencing roulette on the one hand and probability of detection roulette on the other. As we saw earlier, the existing legal system rejects the sentencing roulette but endorses the probability of detection roulette. The current system is justified only if criminals are risk loving with respect to sentences but risk averse with respect to the probability of detection. There are indeed good reasons to believe so. As demonstrated above, criminals are likely to be risk loving with respect to terms of incarceration because of their disposition to discount future costs. Hence, predictable (fixed) terms of incarceration (e.g., 2 years in prison) are likely to deter individuals more than risky terms with the same expected length ( $50 \%$ of 1 year in prison and $50 \%$ of 3 years in prison). In other words, due to the discounting of the future criminals are likely to value the year they may gain by the lottery (the second year in prison) more than the year they may lose by the lottery (the third year) and hence they are likely to prefer a lottery over a fixed term in prison.

The infliction of fines requires a different analysis since unlike years in jail the entire fine is paid at once. There is however theoretical support for the view that criminals are risk-loving also with respect to fines. One of the major findings of prospect theory is that individuals are (typically) risk-averse with respect to gains but risk-loving with respect to losses. To determine whether a person is risk-averse or risk-loving one ought first to identify whether the agent perceives the decision as involving a loss or a gain. The subjective perception of a decision as involving a gain or a loss is often highly sensitive to the way the decision is described to the agent and to the context in which the decision is being made. Thus, if individuals face a choice between an $80 \%$ probability of gaining $\$ 100$ or receiving (for certain) $\$ 80$ they would prefer receiving $\$ 80$. In contrast, if individuals face a choice between an $80 \%$ probability of losing $\$ 100$ or losing (for certain) $\$ 80$, they would prefer the lottery to the loss.

Punishment is naturally understood as a cost and consequently, under prospect theory one would expect criminals to be risk loving with respect to a sentencing lottery 
involving fines. These observations support the existing legal regulation of uncertainty under which sentences are certain and predictable and probabilities of detection are not.

Yet, given the sensitivity of risk propensities to the 'framing' of the decision as involving either a loss or a gain, one may reach also other conclusions. In an experiment designed to examine the risk propensities of individuals to criminal fines, it was found that the transition from a certain/predictable schemes of fines to a risky scheme of probabilistic fines increased rather than decreased the effectiveness of deterrence. ${ }^{23}$ One possible explanation is that individuals do not evaluate the sanction in isolation; instead they evaluate it in conjunction with the expected benefits of the crime. In deciding whether to commit a crime individuals discount the costs (fines) from the benefits and, if the sum is positive, they treat their decision as a decision involving gains. Prospect theory would in such a case predict that criminals would be risk-averse, and if they are risk-averse the optimal sanction ought to be probabilistic.

This example illustrates that behavioural science predictions are often not well defined. Punishment is clearly a cost to individuals who commit crimes. But it cannot be assumed without further investigation that criminals treat punishment as a cost or that their risk propensities with respect to criminal sanctions are aligned with the predictions of prospect theory concerning losses. What determines whether a person is risk-averse or risk-loving is the framing of the decision by the agent as a gain or a loss and not any external or 'objective' judgment as to its nature. As one theorist argued: '[w] hile the predictions of prospect theory are clear once a reference point has been established... it is far less clear what constitutes a reference point. ${ }^{24}$

\section{How to enrich the State by using prospect theory}

Tax evasion is among the most common criminal offences and many resources are invested in an effort to reduce its scope. Behavioural scientists believe that prospect theory may be used to reduce the scope of tax evasion. ${ }^{25}$

As mentioned above, prospect theory predicts that individuals have differential attitudes towards risk. Risk attitudes are different in cases in which the decision involve probabilistic gains and cases in which the decision involves probabilistic losses. While

23 Baker, Harel and Kugler, The Virtues of Uncertainty in Law: An Experimental Approach, in Iowa L. Rev. 89:457-68 (2004).

24 Teichman, The Optimism Bias of the Behavioral Analysis of Crime Control, in University of Illinois L. Rev. 1696 (2011). This is part of a larger concern raised by Teichman, namely the concern that some cognitive phenomena are indeterminate. I investigate this concern at greater length below.

25 Yaniv, Tax Compliance and Advance Tax Payments, in National Tax Journal 52:753 (1999) pp. 1700 - 1701, see also Guthrie, Prospect Theory, Risk Preference and the Law, in Northwestern University L. Rev. 97:1115, 1142-45 (2002-2003). 
individuals are risk averse with respect to gains, they are often risk loving with respect to losses.

Tax evasion can be described as a lottery. The individual faces a choice to pay his taxes or to pay a smaller amount but to face a risk that, if caught, he would be subject to a large fine. The inclination to take risks hinges on the question of whether individuals perceive the lottery as a lottery designed to increase their gains or to reduce their losses. Further, the state can influence (at least to some extent) whether the lottery is perceived as minimising losses or maximising gains. Thus, the state can partially control the risk attitudes of individuals and manipulate them to promote its ends, namely to reduce tax evasion.

One instrument used by the state is advance tax payment. The state deducts money during the year and, at the end of the year, the taxpayer is required to provide an annual report of his income. If the income is larger than the evaluation on the basis of which the advance payments were made, the taxpayer pays the difference to the state. If the income is lower than the evaluation on the basis of which the advance payments were made, the tax authorities pay back the difference to the taxpayer. Should the state make a high evaluation of the income (and therefore most likely return money to the taxpayer at the end of the year) or should it make a low evaluation of the income (and charge the difference from the taxpayer at the end of the year)?

Prospect theory would recommend that the state make a high evaluation. High advance tax payments mean that tax evasion is a lottery over gains rather than losses. The taxpayer has already made the payment and he expects to get a return which, it is likely, will be perceived by him as a gain. Given the prediction of prospect theory that individuals are risk loving with respect to losses, one may expect that individuals would be more inclined to engage in tax evasion under a scheme in which the advance payments are small (and therefore the lottery involves losses) than in a scheme in which the advance payments are high (and therefore the lottery involves gains). Deterrence considerations suggest therefore that the state ought to prefer a system in which advance payments are high over a system in which advance payments are low, as high advance payments will result in greater compliance with the law.

\section{Prediction postdiction and the law}

Much of the discussion so far has focused on uncertainty. One of the interesting findings related to decision-making in uncertain situations is the differential treatment of future versus past uncertainty. ${ }^{26}$ Psychological research suggests that individuals are less willing to bet on past events than on future events.

Assume that you have to bet on the result of tossing a die. In one case the die has already been tossed while in a second case the experimenter is going to toss it. It seems as

26 Guttel and Harel, Uncertainty Revisited: Legal Prediction and Legal Postdiction, in Michigan L. Rev. 107:467 (2008). 
if there is no difference between the cases. The probability of guessing correctly in both cases is identical. However, experimental research indicates that individuals react differently in these cases. ${ }^{27}$ In another famous experiment, subjects were asked to choose between two possible bets: one involved guessing whether a particular stock had increased or decreased in value on the day prior to the experiment and the second involved guessing whether a particular stock would increase or decrease in value on the day after the experiment. The results indicated that $70 \%$ of individuals preferred the second bet. ${ }^{28}$ It is shown below that the social planner can use the differential attitudes toward the past and future uncertainty in order to increase the deterrent effects of criminal law.

Precautions against crime are divided into two types. Some precautions operate before the crime is committed (e.g., cameras and LoJacks). Other precautions operate after the crime is committed (e.g., police patrols). The empirical findings concerning uncertainty indicate that precautions of the first type are more effective than precautions of the second type. In the case of the first type of precautions, the criminal bets on precautions, which operate at the time the offence is committed. He is asked therefore to bet on a die that has already been tossed, e.g., on the question of whether a camera documents his behaviour. In the case of the second type of precautions, the criminal is asked to guess the probability of a future event, e.g., a police patrol. The differential treatment of prediction and postdiction suggests that criminals are more likely to bet in the second case than in the first. Consequently, the first type of precautions is more effective.

One way to illustrate this point is to re-examine the operation of tax enforcement authorities. Typically, tax authorities use samples of individuals who are selected randomly. The sample is selected at the end of year. Taxpayers who consider committing fraud bet on the future; they bet that their names will not come up in the sample. It is easy to see how the system can change such that taxpayers bet on the past rather than on the future. If the lottery takes place not at the end of the year but at the beginning of the year, the taxpayers bet not on the question of whether their names will come up on the sample but whether their names already appear in the sample. This latter bet has greater deterrent effects.

\section{The availability heuristic and criminal law}

The traditional economic approach explores the influence of the size of sanctions and the probability of detection on deterrence. Behavioural economists argue that deterrence is not a product of the actual size of a sanction or the probability of detection but a product of the beliefs concerning the size of the sanction and the probability of detection. Can

27 Rothbart and Snyder, Confidence in the Prediction and Postdiction of an Uncertain Outcome, in Can.J.Behav.Sci. 2: 38 (1970).

28 Heath and Tversky, Preference and Belief: Ambiguity and Competence in Choice under Uncertainty (Stanford University 1990) pp. 5 - 28. 
we examine how these beliefs are formed and shaped? Can we affect the content of these beliefs?

Some (and perhaps most) readers of this article have considered once or twice in their life whether to speed or to park illegally. ${ }^{29}$ In such cases those readers also thought of the potential risks of such behaviour: the risk of being fined. But (with the possible exception of the fine for illegal parking) it is likely that the readers did not know the precise sanctions for such behaviour and certainly did not know the probability of detection.

How did those who decided to speed (or not to speed) or to park illegally and risk a fine (or drive for the third time around the block and look for a legal parking space) form their decision? There is perhaps one parameter that influences greatly such a decision. If on the evening before the event, one of your friends complained about getting a speeding ticket or you read in the paper a report on a police campaign against speeding, you are more likely to comply with the law. Psychologists call this phenomenon availability. The term 'availability' denotes the disposition of individuals to form their beliefs on the basis of anecdotal information, which they can easily recall from memory. ${ }^{30} \mathrm{~A}$ famous example corroborating the availability heuristic is based on the following experiment. Individuals are asked how many seven-letter words in a 2,000-word section of a novel end in 'ing' give much larger estimates than individuals asked how many words in such a section have ' $n$ ' as the second-to-last letter, despite the fact that objectively there are more words which satisfy the latter than the former. It is simply the case that individuals can more easily recall examples of the former type of words than the type of the latter. More relevant for us is the finding that people tend to overestimate vivid/salient risks, such as car and plane accidents, school shootings, nuclear accidents, and underestimate less visible or publicised risks, such as heart disease. The former are well publicised and therefore people tend to overestimate the prospect that they may occur.

Our beliefs concerning the size of sanctions and the probability of detection are not formed by reading the penal law or reading the annual statistics collected by the police. Empirical findings show that individuals have little information both with respect to the size of the criminal sanctions and with respect to the probability of detection. ${ }^{31}$ Instead these beliefs are often formed by a story we read in the news or an anecdote told by a neighbour.

Some theorists proposed to use the availability bias to reduce the rate of illegal parking by using colourful and visible parking tickets. The argument is that neighbours and

Interestingly this was the trigger for the seminal article on the subject of criminal law and economics by Becker, see Becker 1997 pp. 38, 41. It seems that the only offence that can excite the minds of professors are speeding or parking offences.

30 Tversky and Kahneman, Availability; A Heuristic for Judging Frequency and Probability, in Cognitive Psychology 5:207 (1973).

31 Robinson and Darley, Does Criminal Law Deter? A Behavioral Science Investigation. in Oxford Journal of Legal Studies 24:173-205 (2004). 
pedestrians will remember such tickets, thus creating great deterrent effects. ${ }^{32}$ More generally, this view would imply that to be effective, enforcement activity ought to be salient and vivid such that it will be registered in the minds of potential criminals. The availability bias also suggests that the public punishments used in the Middle Ages (e.g., public flogging or public execution) was congenial to deterrence not because it provided accurate information concerning the probability of detection, but because it provided a memorable and salient reminder to individuals of the risks of conviction. Imposing overly harsh sanctions and publicising this fact may arguably be conducive to deterrence for this reason. ${ }^{33}$

It has also been pointed out that the availability heuristic influences not only potential criminals but the public opinion and this may lead to sub-optimal legislation or sub-optimal law enforcement policies. One theorist argued, for instance, that 'in criminal law, street crime (theft and violent crime) is especially vivid and frightful for most people. In contrast, white-collar crimes, such as financial frauds in which many victims lose small amounts, seem much less threatening. ${ }^{34}$

The availability heuristic may affect not only decisions by people subject to the law, but also the decisions of policy-makers. Judges may impose harsher sanctions on criminals who have committed crimes that are salient. Crimes that they can easily recall from the press may be perceived as more threatening. More particularly they may perceive such crimes to be more common that they really are. Anecdotal evidence may influence their judgments in ways that do not accurately reflect the reality. Interest groups may exploit the availability heuristic by using anecdotal evidence designed to affect public opinion. For instance, potential victims of crime may overinvest in precautions against crime due to the intentional manipulation on the part of firms expected to gain from selling such precautions. To do so, such firms need not lie about the frequency of crime; they simply need to publicise anecdotal horrific stories concerning crime.

\section{Over-optimism and criminal law}

One of the persistent finding of behavioural scientists is that individuals tend to be over-optimistic. For instance it was noted that individuals tend to believe that they are very unlikely to divorce even at the face of the statistics indicating a very high rate of divorce. It has been claimed that over-optimism weakens deterrence by both causing po(1998) p. 1538.

33 Legal theorists have used this argument to justify the imposition of capital punishment. It was argued that given the salience of capital punishment, it would be highly effective, see Sunstein and Vermeule, Is Capital Punishment Morally Required? Acts, Omissions, and Life-Life Tradeoffs, in Stan L. Rev. 58:703, 714 (2005) p. 714.

34 Brown, Costs Benefit Analysis in Criminal Law, in California L. Rev. 92:323, 342 (2004) p. 342. 
tential criminals to overestimate the benefits resulting from crime and to underestimate the probability of detection and the size of the sanctions..$^{35}$

Policy-makers ought to take these factors into account in determining the size of the expected sanction, and impose a harsher expected sanction than the sanction sufficient to deter individuals who calculate correctly the expected costs and benefits of crime. One may doubt, however, the degree to which the optimism bias should be used by policymakers. As potential criminals often have no knowledge concerning the probability of detection, it is not necessarily the case that one can take the actual probabilities of detection as a starting point and infer that criminals' subjective assessments of the probability of detection are lower. It was also pointed out that over optimism may cause criminals to underinvest in precautions, i.e., to be less careful; and such underinvestment on their part may be conducive to law enforcement. ${ }^{36}$ Further over-optimism may also affect the behaviour of victims of crime and cause them to undervalue the risks of crime and consequently to underinvest in precautions against crime. This may require policy-makers to increase rather than decrease sanctions. The different effects of over-optimism on criminals and on victims of crime make it particularly difficult to know whether overall criminal sanctions ought to be harsher or lighter than the sanctions sufficient to deter individuals who calculate correctly the expected costs and benefits of crime.

Last, over-optimism may affect judges who may over-estimate the deterrent effects of sanctions and thereby impose harsher sanctions than optimal. They may therefore be too optimistic as to the influence of sanctions on the frequency of crimes and therefore impose sanctions that are excessive. Drawing attention to over-optimism of judges may perhaps 'de-bias' judges, namely enable them to provide more accurate evaluations and thus to be more realistic about the limitations of criminal sanctions.

Positive criminal duties: the duty of rescue

Criminal law typically consists of negative duties: it prohibits individuals from committing murders, thefts, and rapes. Liberal criminal law theorists are reluctant to impose positive duties. Yet this reluctance is not universally accepted. The approach of common law systems on the one hand and European or religious systems on the other hand is different; the former systems are much more reluctant to impose a duty of rescue. Positive duties exist in criminal law even in common law systems, but they typically hinge on the existence of prior relationships (such as the parent-child relationship) or special circumstances (such as drivers who observe a traffic accident). A classic case illustrating the common law's reluctance to impose positive duties is its refusal to embrace so-called 'good Samaritan' duties - i.e., duties to rescue. ${ }^{37}$

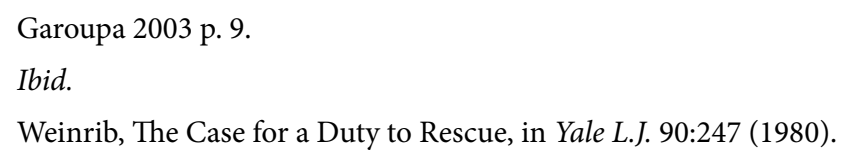


Traditionally, the reluctance to impose positive duties is justified on grounds of autonomy. The legal system ought to protect the 'negative liberty' of individuals but it cannot dictate to them what to do. Richard Posner and William Landes think that legal responsibility for failing to rescue characterises communist or fascist legal systems, because the imposition of responsibility is a form of 'conscription for the social service. ${ }^{38}$ Under this view, individuals ought to be legally required not to cause harm to others but they ought not to have any legal obligations whatsoever to help others. Can the absence of positive duties in the common law be justified?

Arguably, it is very difficult to explain the absence of positive duties on economic grounds. The utilitarian tradition, which provides the normative foundations for economic analysis of law, imposes very demanding duties on individuals. Maximising utility requires one individual to help another as long as the marginal utility resulting from one's efforts is greater than the costs. My duty is therefore to serve the beggars of Jerusalem instead of sitting in my air-conditioned office and writing this text. ${ }^{39}$ Naturally, it does not follow that the legal system ought always to impose such duties, as sometimes there are grave costs to legal enforcement. Yet it is quite difficult to explain in economic terms why, if I sit on the beach watching birds while my desperate friend is struggling to save his life in the water, the law ought not impose a legal duty to interrupt my favourite hobby and throw a rope to save him.

It is evident that often individuals engage in rescue even without a legal duty to do so. ${ }^{40}$ But it seems that imposing legal sanctions would increase the willingness to rescue. One challenge to this view rests on behavioural conjectures, and especially on the influential conjecture of Richard Titmuss in his famous book, The Gift Relationship from Human Blood to Social Policy. ${ }^{41}$ In this book, Titmuss identifies a psychological phenomenon that he labels 'crowding out'. Titmuss explores the practice of blood donations, comparing the American practice (in which blood donors receive monetary compensation) with the British practice (in which blood donors get no such compensation). Titmuss found that the willingness to donate blood in Britain is greater than the willingness to donate blood in the U.S. despite the absence of monetary compensation in Britain. His claim (which is highly controversial) is that monetary compensation reduces or annuls altruistic incentives, and therefore, the blood supply in a society in which blood donors receive monetary compensation may be lower than in a society in which blood donors receive no such compensation.

\footnotetext{
38 Posner and Landes, Altruism in Law and Economics, in American Economic Review 68:417 (1972).

39 Hills, Utilitarianism, Contractualism and Demandingness, in Philosophical Quarterly 60:225 (2010).

$40 \quad$ Heyman, Rescue Without Law: An Empirical Perspective on the Duty to Rescue, in Texas L. Rev. 84:653738 (2006).

${ }_{41}$ Titmuss, The Gift Relationship: From Human Blood to Social Policy, eds. Oakley and Ashton (New Press 1997).
} 
Titmuss focuses his attention on monetary incentives 'crowding out' altruistic motivations, but his hypothesis can apply also to legal (and in particular criminal) sanctions 'crowding out' the same altruistic motivations. Under this view, by imposing a criminal law duty, law may weaken rather than strengthen the disposition of individuals to invest in rescue. Individuals may invest in rescuing precisely because they perceive it as a moral duty. Imposing legal responsibility for failing to rescue may turn the act from an act of charity, indicating the virtues of the rescuer, into an act that is merely done out of compliance with the law. Hence, legal sanctions may 'crowd out' the altruistic motivations and thus reduce the willingness to rescue. ${ }^{42}$

\subsubsection{Sociological findings and criminal law}

\section{Criminal law and social norms}

Social Norms Theory is based on the conjecture that there is an interaction between law and social norms. This view rejects the equation of criminal law sanctions as costs that decrease the inclination of criminal behaviour. While criminal law sanctions are also costs they are not only costs. Instead, the legal sanction itself influences individual preferences and social attitudes, and much of the influence of criminal law hinges on the resulting changes in preferences and also social pressures and stigma.

One branch of the social norms movement maintains that criminal behaviour is not determined primarily by the size of sanctions or the probability of detection. A person's criminal behaviour is influenced to a larger extent by the behaviour of other members of the person's social group, the rate of compliance in the society as a whole, perceptions of the justness of the legal system, etc. ${ }^{43}$ The view under which law is merely an external incentive whose size is determined by legal sanctions does not reflect reality. In fact, there is an ongoing interaction between legal norms and social norms. The legal norms and the size of the sanctions inflicted on violators influence one's inclinations to perform the act and her perception as to whether such an act is morally appropriate. The effectiveness of the enforcement of criminal law norms determines to a large extent the social attitudes towards the legal norms and, in particular, the social norms governing behaviour.

A famous example identified with the social norms movement can illustrate these conjectures. The 'broken windows' metaphor is used to convey the idea that the willingness of individuals to obey the law depends on their environment. In particular, the theory posits that minor violations - graffiti, abandoned buildings, garbage, etc. - regularly

42 This conjecture may also be supported by Gneezy and Rostechini, A Fine is a Price, in Journal of Legal Studies 29:1-17 (2000). In this case it was documented that once a fine was imposed on parents who are late in picking up their children from day-care, the amount of late arrivals increased.

43 Posner, Law and Social Norms (Harvard University Press 2000), Kahan, Social Influence, Social Meaning and Deterrence, in Virginia L. Rev. 83:349 (1997). 
encourage criminal activity. ${ }^{44}$ This conjecture led the former mayor of New York City, Rudy Giuliani, to strictly punish such minor violations, as he believed that individuals adjust their behaviour not to the expected sanction but to the norms of behaviour prevailing among their neighbours and friends. ${ }^{45}$

In a famous experiment, the psychologist Phillip Zimbardo left a car with a broken window unattended and documented the resulting vandalism. Zimbardo found that the car had a negative effect on the behaviour of individuals. ${ }^{46}$ The influence of social norms has different explanations, some of which can be accommodated within the frame of neo-classical economics. One explanation is the 'signalling' theory. Under this theory, individuals gain information from their environment with respect to the level of enforcement. Thus, minor violations (such as graffiti or broken windows) signal to individuals that the social order has collapsed and the probability of detection is low; therefore, crime is beneficial. Another explanation is based on the stigma effects of minor violations. If stigma is affected by the crime rate, a high rate for a crime indicates that there is no stigma attached to the crime.

Despite these observations it is important to note that these observations are highly controversial; the 'broken windows' theory was used to promote a right-wing political agenda and its implications have often therefore been exaggerated. One can nevertheless appreciate its scientific soundness without supporting the wild conjectures made by its ideological proponents.

\subsection{Summary and critique}

Part 3 provided various examples for the use of behavioural phenomena to understand the effects of legal rules and the effects of evidence rules and law enforcement policies. Further it also indicated how the lawmakers and policymakers can make use of these phenomena in designing laws and policies. Note that this section illustrates a central feature of the behavioural analysis of law, namely, that in contrast to traditional or classical law and economics behavioural law and economics does not have a single unifying theory. It is based on numerous empirical and experimental findings. Applying those to the field of criminal law often requires sensitivity to circumstances and context, and should be done with caution. Mechanical application of psychological and sociological findings without examining their relevance to the criminal context is often misguided.

The primary accusation of behavioural scientists is that traditional advocates of law and economics blinded themselves to the realities of law and criminality. More specifically they argue that criminals are not self-interest maximisers, and do not operate in the 
ways attributed to them by economists. At best, we ought to complement traditional law and economics by examining what the real beliefs and preferences of criminals are. At worst, we ought to reject some of the premises of economic models. This article identified numerous behavioural phenomena that are relevant to the analysis of criminal law. These phenomena are only representative illustrations and many more could be discussed.

I wish to devote this part to raise some critical comments on the behavioural movement and the applicability of its findings to criminal law. The behavioural analysis examined above is subject to criticisms of two types: internal and external. Among the internal criticisms, one may mention specifically what one theorist labelled 'indeterminate biases', namely the use of terms that acquire precise meanings only in specific contexts such as gains or losses in prospect theory. ${ }^{47}$ As illustrated above there is no natural way to classify punishment and it could be classified either as a loss if looked at separately or as a gain if looked at in conjunction with the gains resulting from the crime. This is not unique to the case of punishment, and it raises doubts as to the potential contribution of prospect theory to policy-making. ${ }^{48}$ Further it was pointed out that the multiplicity of biases generates uncertainty as some of these biases may offset one another. People may for instance be over-optimists (and therefore underestimate the probability of detection) but, at the same time, be subjected to an availability bias which leads them to overestimate the probability of detection. It is difficult to predict under such circumstances which among conflicting biases is stronger or more effective. ${ }^{49}$

Beyond these internal objections, there is a sense that behavioural law and economics treats individuals mechanistically. Punishment is designed to 'train' the criminal. Concepts such as autonomy or choice, which are so central to criminal law, do not have a place within the behavioural tradition. Ironically, in the long run this view may erode the effectiveness of criminal law and, in particular, the effectiveness of the stigma attached to crime. If criminal law is nothing but a system of incentives whose effectiveness hinges on manipulation, fraud and cognitive biases (rather than a system of norms designed to guide individuals and aid them in deliberating on what ought and what ought not to be done), individuals would inevitably lose any feelings of shame or guilt or respect towards the criminal law. Instead, they would treat criminal law in the same way they treat powerful thugs. Such thugs inevitably intimidate, but their judgments do not guide individuals and their commands are disobeyed whenever it is safe to do so.

Last, some criminal law theorists believe that punishment is designed to cause pain to individuals and not only to deter them. Punishment is about retributive justice and it

\footnotetext{
47 See Teichman 2011 pp. 1700 - 1704

48 For an attempt to address this objection, see Zamir, Loss Aversion and the Law, in Vanderbilt L. Rev. 65:829 (2012) pp. 889 - 892.

$49 \quad$ See Teichman 2011 pp. $1704-1706$.
} 
Harel

seems that retributivism has no place either in the classical law and economics tradition or in behavioural law and economics.

\section{$4 \quad$ Concluding remarks and future challenges}

I will not deceive the reader by denying that the behavioural analysis of criminal law has so far had very limited effect on legal practice. There are very few fields in which economic analysis in general and behavioural analysis in particular had lesser impact than in the field of criminal law.

Perhaps, as I argued in a different context, the reason is the great interest of the public in criminal law (in contrast to other more technical fields of law). Criminal law deals with murder, robbery, blood, and love and beneath the gowns of judges one can sense intense passions and human sentiments..$^{50}$ The smell of blood, sweat and sperm can barely be disguised when criminal law is at stake. Economics and behavioural economics seem too impoverished to govern this field where death, blood, sex, love and hatred intermingle with each other. Perhaps philosophers rightly observe that retributivism is a primitive sentiment that ought to be overcome. But nobody has yet taught us how to do this, and the public and the legislature do not pay attention the pleadings of philosophers.

Furthermore, beyond the positive or negative effects of criminal law prohibitions on human behaviour, it is still the case that the existence of criminal law prohibitions (independent of what they are or what their effects are) serves, as Durkheim observed, to reinforce social solidarity. Durkheim believed therefore that society needs crime. To illustrate why Durkheim said:

\footnotetext{
Imagine a society of saints, perfect cloister of exemplary individuals, crimes, properly so called, will there be unknown; but faults which appear venial to the layman will create there the same scandal that the ordinary offence does in ordinary consciousness. If, then, this society has the power to judge and punish, it will define these acts as criminal and treat them as such. ${ }^{51}$
}

Criminal law is not merely a means of training and inducing individuals to behave; it maintains and protects the social framework. This function cannot easily be translated into the language of economics or psychology.

These observations do not imply that economic or behavioural insights cannot be useful, but merely that their effects are at least ordinarily limited to the more technical aspects of criminal law, such as regulatory or white collar offences. Legal doctrine will continue to be governed by the Freudian id rather than by the rational ideals of social

See Harel 2012.

Durkheim, The Rules of Sociological Method, translation by Solovay and Mueller, ed. Catlin (Free Press of Glencoe 1964). 
scientists. I also dare say that this is not merely a prediction but also a hope. Criminal law is the field where the ideals of freedom and autonomy are particularly important. As mentioned above, the behavioural approach sharply conflicts with this view; criminal law is understood to be about training individuals to behave according to the norms rather than teach them about what is right and wrong and guide them in their moral deliberations. Such an approach undermines the pretence of the criminal law to guide us, to aid in deliberating and to provide an inspiration.

This is but an example of a gap in the literature on the behavioural analysis of law. More specifically I want to urge social scientists and legal theorists to think harder what the normative significance of our preferences is. Precisely as in the context of criminal law I pointed out a tension between the ideals of autonomy and freedom of choice and the behavioural approach to criminal law, so such tensions can be found in other fields. Contract law theorists influenced by behavioural studies urge us to differentiate between our 'true' preferences and those resulting from cognitive biases. Ultimately to know what we really want, we ought to launder the preferences and beliefs, to purify them. But the more successful behavioural scientists are in pointing out biases and misperceptions the less the faith one has in the very existence of independent and authentic preferences that merit respect. 